Article

\title{
Hydrophobic Agglomeration of Fine Pyrite Particles Induced by Flotation Reagents
}

\author{
Wanli Cheng ${ }^{1,2,3} \mathbb{C}$, Zhengbin Deng ${ }^{1,2,3,4, *}$, Xiong Tong ${ }^{4,5}$ and Tianshen Lu ${ }^{1,2,3}$ \\ 1 College of Mining, Guizhou University, Guiyang 550025, China; wanli1530@163.com (W.C.); \\ lutianshen1210@163.com (T.L.) \\ 2 National \& Local Joint Laboratory of Engineering for Effective Utilization of Regional Mineral Resources \\ from Karst Areas, Guiyang 550025, China \\ 3 Guizhou Key Laboratory of Comprehensive Utilization of Non-metallic Mineral Resources, \\ Guiyang 550025, China \\ 4 State Key Laboratory of Complex Nonferrous Metal Resources Clean Utilization, Kunming 650093, China; \\ kgxiongtong@163.com \\ 5 Faculty of Land and Resource Engineering, Kunming University of Science and Technology, \\ Kunming 650093, China \\ * Correspondence: zbdeng@gzu.edu.cn; Tel.: +86-851-8362-7275
}

Received: 2 August 2020; Accepted: 9 September 2020; Published: 11 September 2020

check for updates

\begin{abstract}
Flotation reagents can change the surface properties of minerals, leading to differences in the interaction between mineral particles and affecting the mutual aggregation or dispersion of particles. In this work, we studied the role of activator copper sulfate, collector butyl xanthate and frother terpineol in adjusting the potential energy of pyrite particles from the perspective of the interfacial interaction. We evaluated the surface characteristics using contact angle analysis and zeta potential measurements under different reagents. A microscope was used to observe aggregation state of particles. The hydrophobic agglomeration kinetics of pyrite was studied through the turbidity meter measurement, and the interaction energy between pyrite particles was calculated using the extended-Derjaguin-Landau-Verwey-Overbeek (extended-DLVO) theory. The results showed that the repulsive potential energy is dominant among pyrite particles in aqueous suspensions and that the particles are easy to disperse. Flotation reagents can effectively reduce the repulsive energy between pyrite particles and increase the attraction energy between particles, which is conducive to the hydrophobic agglomeration of fine pyrite. Reagent molecules can greatly reduce the electrostatic repulsion potential energy of the pyrite particles' interface, increase the hydrophobic attraction potential energy between the particle interfaces, and its size is 2 orders of magnitude larger than the van der Waals attraction potential energy, which is the main reason for induced the agglomeration of fine pyrite and is conducive to the flotation recovery of fine pyrite. Generally, the order in which the reduction of pyrite agglomeration was affected by the additions of flotation reagents was butyl xanthate $>$ terpineol $>$ copper sulfate.
\end{abstract}

Keywords: fine pyrite; flotation reagents; hydrophobic agglomeration; extended-DLVO theory

\section{Introduction}

Crushing and grinding are essential processes in mineral processing and production. The process of separating useful minerals from ore mineral, a large number of fine minerals will inevitably be produced [1]. Selective recovery of fine particles smaller than $10 \mu \mathrm{m}$ remains a significant challenge in the mineral industry. Flotation is the primary technology for selective separation of fine pyrite. The flotation efficiency is related to particle size, and the flotation response of pyrite falls substantially when the particles are present in a fine size range [2]. This is due to the flotation of fine particles 
that can cause problems like high reagent consumption, lower collision and adhesion probability between particles and air bubbles, non-selective collector adsorption, and mechanical entrainment. The interaction between the particles causes the selective aggregation or dispersion of fine pyrite, affecting the separation effect $[3,4]$. The separation effect can be effectively improved by enhancing the hydrophobicity of the pyrite surface, inducing selective hydrophobic aggregation of fine pyrite, and increasing the apparent particle size [5].

In the aqueous solution, the hydrophobic particles agglomerate due to the strong hydrophobic attraction between the particles [6]. Lu's research shows that the stronger the surface hydrophobicity of the particles, the greater the potential energy for hydrophobic interaction between the particles and the higher the degree of agglomeration [7]. The hydrophobilization of pyrite particle surfaces can be realized by surfactant adsorption. After the reagents were adsorbed on the mineral surface, the interaction between the mineral particles changes significantly [8]. There are many reports available on the hydrophobic flocculation of pyrite fines induced by surfactants. For example, in the presence of isobutyl xanthate (SIBX) and dithiophosphate (DTP) collector mixture, pyrite agglomerate in the acid medium [9]. In the presence of metal ions $\mathrm{Ca}, \mathrm{Pb}$ and $\mathrm{Fe}$ (II), the largest agglomeration of pyrite occurs near the isoelectric point (IEP) [10]. In the sodium hexametaphosphate aqueous solution, due to the adsorption of negatively charged phosphate ions, the van der Waals attraction energy between particles decreases and the electrostatic repulsion energy increases. As the distance approaches, the hydration repulsion energy increases rapidly, the total interaction is characterized by strong repulsion, and aggregation between particles does not easily occur [11]. When ethanol is used as the medium, the interaction energy of the pyrite particles is higher than the absorbing energy at the interaction distance of over $5 \mathrm{~nm}$. When the distance is over $10 \mathrm{~nm}$, the electrostatic repulsion energy was dominant, and when the distance is less than $5 \mathrm{~nm}$, the hydrophobic attraction energy is dominant [12]. In heptane solution, when the interaction distance between pyrite particles exceeds $2 \mathrm{~nm}$, the hydrophobic interaction energy dominates the particles. If it is shorter than this distance, van der Waals dominates [13]. Reagents have a significant effect on the interaction between mineral particles. However, there are few reports available on the hydrophobic agglomeration behavior of fine pyrite by common flotation reagents such as activator copper sulfate, collector butyl xanthate and frother terpineol. Therefore, it is important to make clear that these traditional flotation reagents have an important influence on the efficient flotation recovery of fine pyrite.

Based on this, in order to explore the effect of flotation reagents on the hydrophobic agglomeration of fine pyrite, the surface electrical properties, surface wettability, and agglomeration of pyrite under different reagent systems were investigated by Zeta potential measurements, surface contact angle tests, and optical microscope analysis. According to the derivation formula of Young's equation and the contact angle measurement results, the surface energy parameters of pyrite were calculated. The electrostatic interaction energy, polar interaction energy, and total interaction energy of pyrite particles under different flotation reagents were calculated using the extended-Derjaguin-Landau-Verwey-Overbeek (extended-DLVO) theory. From the perspective of interfacial energy, the mechanism of hydrophobic aggregation of fine pyrite by flotation reagents was clarified.

\section{Materials and Methods}

\subsection{Experimental Section}

\subsubsection{Sample Preparation and Reagents}

The pyrite samples used in this study were obtained from Yiliang Chihong Mine, Yunnan Province, China. A chunk of mineral was selected for contact angle measurements. The remaining chunks of minerals were dry-ground in a porcelain ball mill and dry-screened to obtain the fine pyrite. The mineral compositions of pyrite were analyzed by X-ray diffraction (XRD, Bruker D8, Bruker AXS, Inc., Madison, WI, USA). The results of X-ray diffraction (Figure 1) and multi-element chemical analyses (Table 1) 
confirmed that the purity of the pyrite sample was more than $95 \%$. The particle size distribution of pyrite samples measured by laser particle size analyzer (Beckman Coulter, Inc, Miami, FL, USA) was shown in Figure 2. The results indicate that the dominant sizes of the fine pyrite were about $6.17 \mu \mathrm{m}$.

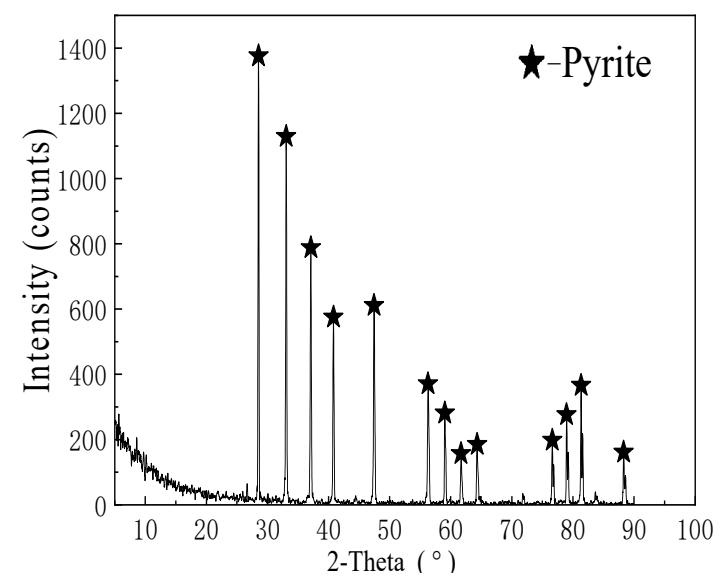

Figure 1. X-ray diffraction patterns of pyrite.

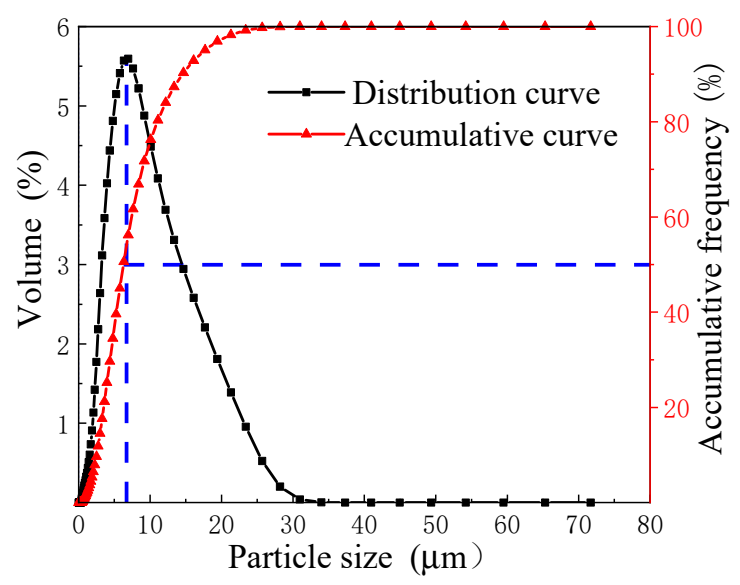

Figure 2. Particle size distribution of pyrite.

Table 1. Chemical composition of pure minerals.

\begin{tabular}{lcccccc}
\hline Composition & $\mathbf{F e}$ & $\mathbf{S}$ & $\mathbf{Z n}$ & $\mathbf{P b}$ & $\mathbf{S i O}_{2}$ & Others \\
\hline Contents $/ \%$ & 46.41 & 53.24 & 0.04 & 0.01 & 0.17 & 0.13 \\
\hline
\end{tabular}

In this study, sodium butyl xanthate (Sinopharm Chemical Reagent Co., Ltd., Shanghai, China) was used as the collector, terpineol (Coal Preparation Plant, Guizhou, China) was used as the frother, copper sulfate (Zhiyuan Chemical Reagent Co., Ltd., Tianjin, China) was used as the activator. Terpineol is a chemically-pure reagent, the other reagents were analytically grade. Hydrochloric acid $(\mathrm{HCl})$ and sodium hydroxide $(\mathrm{NaOH})$ of analytical grade from Tianjin number 3 Chemical Reagent Factory was used as the $\mathrm{pH}$ regulators. Distilled water was used in all the experiments.

\subsubsection{Flotation Tests}

Single mineral flotation tests were performed with a $40 \mathrm{ml}$ XFG trough-type laboratory flotation machine (Prospecting Machinery Plant, Jilin, China). The impeller speed was fixed at $1800 \mathrm{r} / \mathrm{min}$. The $\mathrm{pH}$ value was measured by the PHS-3C acidometer built by Leici company (Shanghai, China). The single mineral flotation test was prepared by adding $2.0 \mathrm{~g}$ of minerals to $40 \mathrm{~mL}$ of solutions. The $\mathrm{pH}$ 
of the mineral suspension was adjusted to the desired value by adding $\mathrm{NaOH}$ or $\mathrm{HCl}$. After adding the required amounts of reagents, froth flotation was carried out during which a concentrate was collected. The floated and unfloated particles were collected, filtered, and dried. The flotation recovery was calculated based on solid weight distributions between the two products.

\subsubsection{Zeta Potential Measurements}

The zeta potential of pyrite particles was measured with a Coulter Delsa 440sx zeta potential analyzer. After adding $30 \mathrm{mg}$ of sample to $50 \mathrm{~mL}$ of distilled water, a given amount of flotation reagents was added with a conditioning time of $3 \mathrm{~min}$. The suspension was allowed to stand for another $8 \mathrm{~min}$ to allow settling of larger particles. The $\mathrm{pH}$ of suspension was adjusted with $0.1 \mathrm{~mol} / \mathrm{L} \mathrm{HCl}$ or $0.1 \mathrm{~mol} / \mathrm{L} \mathrm{NaOH}$. Then, the supernatant was injected into a test electrophoresis tube with a syringe for measurement. To ensure the accuracy of the results, zeta potential measurements were performed at least five times for each $\mathrm{pH}$ value, and the average value was calculated (the electrolyte used in the experiment was $1 \mathrm{~mol} / \mathrm{L} \mathrm{KNO}_{3}$ solution, and all measurements were conducted at approximately $25^{\circ} \mathrm{C}$ ).

\subsubsection{Contact Angle Measurements}

A cutting machine was used to cut block pyrite into a proper size of approximately $2 \times 2 \times 1 \mathrm{~cm}$. It was then polished using 60, 400, 800, 1000, and 2000 mesh silicon carbide sandpapers, respectively. The lump of the pyrite sample was further polished with a polishing cloth. Contact angles of pyrite were measured using the droplet method with HARKE-SPCAX3 (Beijing Hake Test Instrument Factory, Beijing, China). Lumps of the prepared pyrite sample were immersed in solutions of different reagents at pH 6 for $15 \mathrm{~min}$. Then, the pyrite sample was dried and placed on the test platform. A water droplet with a volume of about $2 \mu \mathrm{L}$ was squeezed out by a syringe and dropped onto the mineral surface. The average of three measurements was taken as the contact angle of the droplet. All the measurements were made at approximately $25^{\circ} \mathrm{C}$.

\subsubsection{Hydrophobic Agglomeration Tests}

Two grams of pyrite were weighed and placed in an XFG laboratory flotation machine with a volume of $40 \mathrm{~mL}$ and stirred with distilled water. Under the action of mechanical stirring, the mineral particles were evenly dispersed. The reagents required for the test were added and stirred for $5 \mathrm{~min}$. The $\mathrm{pH}$ value was adjusted to 6 . While stirring, $2 \mathrm{~mL}$ of the suspension was added dropwise and spread on a microslide. The aggregation state of the particles was observed with a microscope (CX-21, OLYMPUS, Japan).

A turbidity meter (HACH 2100Q, Loveland, CO, USA; the turbidimetric unit is NTU and the turbidimetric of $1 \mathrm{mg} / \mathrm{L} \mathrm{SiO}_{2}$ suspension is $1 \mathrm{NTU}$ ) was available for investigating the kinetics of hydrophobic agglomeration of fine pyrite particles in aqueous suspensions. The pulp was then poured into a $100 \mathrm{~mL}$ settling cylinder, and the volume was diluted to $100 \mathrm{~mL}$. Thereafter, it was shaken up and down six times, and the turbidity of the suspension was measured every minute by a turbidity meter. The $20 \mathrm{~mL}$ suspension at the top of the settling liquid was extracted, and its turbidity was measured in the turbidimeter. The performance of the hydrophobic agglomeration kinetic process was assessed using the turbidity change of pyrite suspension with time. The turbidity of each test was measured three times and then averaged.

\subsection{Theoretical Background}

\subsubsection{Calculation of Solid Surface Energy}

Young's equation [14] describes the relationship among the solid surface energy $\gamma_{\mathrm{S}}$, liquid surface energy $\gamma_{\mathrm{L}}$, solid-liquid interfacial interaction free energy $\gamma_{\mathrm{SL}}$, solid surface pressure $\pi_{0}$ (for the low 
energy surface, $\pi_{0}$ can be negligible [15]) and balance contact angle $\theta$ in the solid-liquid-gas three-phase system as follows.

$$
\gamma_{\mathrm{S}}=\gamma_{\mathrm{SL}}+\pi_{0} \gamma_{\mathrm{L}} \cos \theta
$$

Van Oss [16-19] argued that solid-liquid surface energy $\gamma$ is determined by the Lifshitz-van der Waals component $\gamma^{\mathrm{LW}}$ and Lewis acid-base component $\gamma^{\mathrm{AB}}$, and $\gamma^{\mathrm{AB}}$ consists of Lewis acid component $\gamma^{+}$and Lewis base component $\gamma^{-}$. Therefore, to solid-liquid, the surface energy can be expressed by

$$
\begin{aligned}
& \gamma_{\mathrm{S}}=\gamma_{\mathrm{S}}^{\mathrm{LW}}+\gamma_{\mathrm{S}}^{\mathrm{AB}}=\gamma_{\mathrm{S}}^{\mathrm{LW}}+2 \sqrt{\gamma_{\mathrm{S}}^{+} \gamma_{\mathrm{S}}^{-}} \\
& \gamma_{\mathrm{L}}=\gamma_{\mathrm{L}}^{\mathrm{LW}}+\gamma_{\mathrm{L}}^{\mathrm{AB}}=\gamma_{\mathrm{L}}^{\mathrm{LW}}+2 \sqrt{\gamma_{\mathrm{L}}^{+} \gamma_{\mathrm{L}}^{-}}
\end{aligned}
$$

The relationship between solid-liquid interfacial free energy and solid-liquid respective surface energy can be expressed by

$$
\gamma_{\mathrm{SL}}=\left(\sqrt{\gamma_{\mathrm{S}}^{\mathrm{LW}}}-\sqrt{\gamma_{\mathrm{L}}^{\mathrm{LW}}}\right)^{2}+2\left(\sqrt{\gamma_{\mathrm{S}}^{+} \gamma_{\mathrm{S}}^{-}}+\sqrt{\gamma_{\mathrm{L}}^{+} \gamma_{\mathrm{L}}^{-}}-\sqrt{\gamma_{\mathrm{S}}^{+} \gamma_{\mathrm{L}}^{-}}-\sqrt{\gamma_{\mathrm{S}}^{-} \gamma_{\mathrm{L}}^{+}}\right)
$$

Substituting Equations (2)-(4) into Equation (1), the relationship between solid surface energy, liquid surface energy, and the balance contact angle between them can be obtained.

$$
\left(\gamma_{\mathrm{L}}^{\mathrm{LW}}+2 \sqrt{\gamma_{\mathrm{L}}^{+} \gamma_{\mathrm{L}}^{-}}\right)(1+\cos \theta)=2\left(\sqrt{\gamma_{\mathrm{S}}^{\mathrm{LW}} \gamma_{\mathrm{L}}^{\mathrm{LW}}}+\sqrt{\gamma_{\mathrm{S}}^{+} \gamma_{\mathrm{L}}^{-}}+\sqrt{\gamma_{\mathrm{S}}^{-} \gamma_{\mathrm{L}}^{+}}\right)
$$

If we used $\mathrm{L}_{1}, \mathrm{~L}_{2}, \mathrm{~L}_{3}$ (two of the three must be polar liquid) to represent the three examined liquids, and the contact angles on the surface of pyrite are $\theta_{1}, \theta_{2}, \theta_{3}$. The surface free energy parameters of pyrite can be obtained by solving after bringing in Equation (5). The detailed calculation process is described in the Supplementary Materials File S1.

\subsubsection{Calculation of the Interaction Energy}

When describing the interaction between particles in flotation system, the extended-DLVO theory, which not only accounts for the electrostatic and van der Waals interaction but also includes other interactions such as the polar interfacial interaction, hydrophobic interaction, and so on [20], can explain the hydrophobic aggregation of particles under certain conditions. In the extended-DLVO theory, the total interaction energy $\left(\mathrm{V}_{\mathrm{T}}\right)$ comprises van der Waals interaction $\left(\mathrm{V}_{\mathrm{W}}\right)$, electrostatic interactions $\left(\mathrm{V}_{\mathrm{E}}\right)$, and hydrophobic interaction $\left(\mathrm{V}_{\mathrm{H}}\right)$. It is expressed as follows:

$$
\mathrm{V}_{\mathrm{T}}=\mathrm{V}_{\mathrm{E}}+\mathrm{V}_{\mathrm{W}}+\mathrm{V}_{\mathrm{H}}
$$

For the same kind of particles with radius $(\mathrm{R}, \mathrm{m})$ and particle interaction distance $(\mathrm{H}, \mathrm{nm})$. Figure 3 shows the interaction between mineral particles adsorbed with flotation reagents.

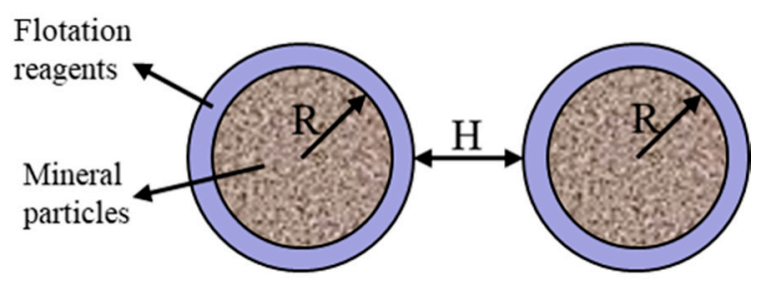

Figure 3. Schematic diagram of interaction between mineral particles.

a. Electrostatic interaction, $\mathrm{V}_{\mathrm{E}}(\mathrm{J})$

$$
\mathrm{V}_{\mathrm{E}}=2 \pi \varepsilon_{\mathrm{a}} \mathrm{R} \varphi_{0}^{2} \ln [1+\exp (-\kappa \mathrm{H})]
$$


where $\varepsilon_{\mathrm{a}}$ is the absolute permittivity of water, in the unit of $\mathrm{F} / \mathrm{m}, \varphi_{0}$ is the electric potential of the mineral surface, which could be obtained by zeta potential measurements, in the unit of $\mathrm{V}, \mathrm{k}$ is the thickness of the electric double-layer.

b. Van der Waals interaction, $\mathrm{V}_{\mathrm{W}}(\mathrm{J})$

$$
\begin{gathered}
V_{W}=-\frac{A_{12} R}{6 H} \\
\text { Where } A_{i}=24 \pi d_{0}^{2} \gamma_{i}^{L W}, A_{12}=\left(\sqrt{A_{1}}-\sqrt{A_{2}}\right)^{2}
\end{gathered}
$$

where $d_{0}$ is the minimum separation distance between the surface of mineral particle and the surface of the bacteria, in the unit of $\mathrm{nm} ; \mathrm{A}_{1}$ and $\mathrm{A}_{2}$ are the hamaker constant of pyrite and water in vacuum, respectively, in the unit of J. $\mathrm{A}_{12}$ is the hamaker constant, in the unit of $\mathrm{J}$.

c. Hydrophobic interaction, $\mathrm{V}_{\mathrm{H}}(\mathrm{J})$

$$
\begin{gathered}
\mathrm{V}_{\mathrm{H}}=-2.51 \times 10^{-3} \mathrm{Rk}_{1} \mathrm{~h}_{0} \exp \left(-\frac{\mathrm{H}}{\mathrm{h}_{0}}\right) \\
\text { Where } \mathrm{k}_{1}=\frac{\exp \left(\frac{\theta}{100}-1\right)}{\mathrm{e}-1}, \mathrm{~h} 0=(12.2 \pm 1.0) \mathrm{k}_{1}
\end{gathered}
$$

where $\mathrm{k}_{1}$ is the incomplete hydrophobic coefficient, $\theta$ is the contact angle, in the unit of ${ }^{\circ}, \mathrm{h}_{0}$ is the attenuation length, in the unit of $\mathrm{m}$. It is worth noting that although the vast majority of evidence supports the existence of hydrophobic interactions between hydrophobic surfaces, the origin of the hydrophobia is still controversial. Therefore, Equation (9) is an empirical expression, which is calculated using the exponential decay model.

\section{Results and Discussion}

\subsection{Microflotation Test}

Through the flotation test, the influence of different reagents on pyrite flotation was examined. Optimal reagent dosage and $\mathrm{pH}$ values were determined, as conditions for subsequent tests. The results of the flotation test are shown in Figure 4.
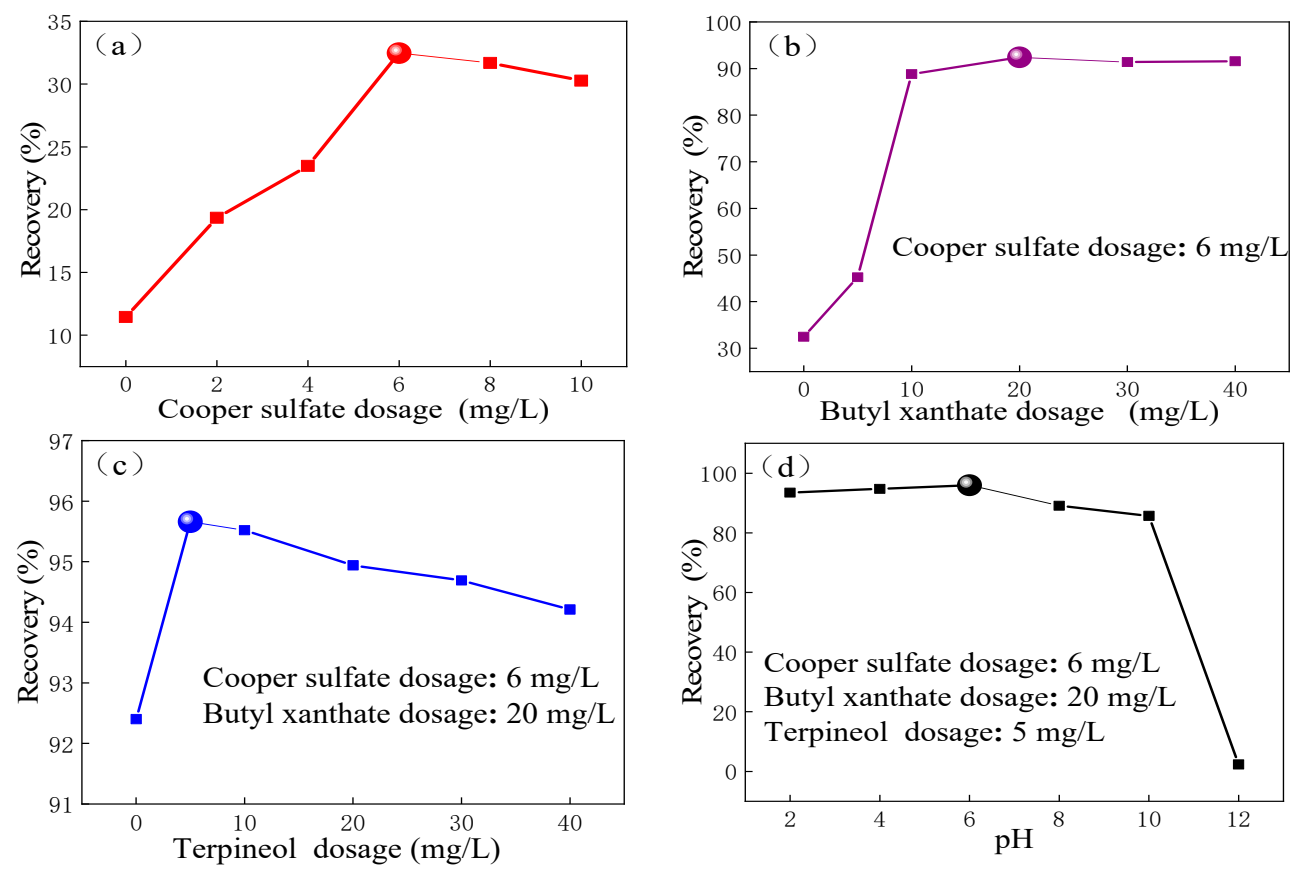

Figure 4. Effect of $\mathrm{pH}$ and flotation reagents dosage on pyrite flotation. (a) Copper sulfate firstly; (b) butyl xanthate secondly; (c) terpineol thirdly; (d) $\mathrm{pH}$ value lastly. 
First, Figure 4 a shows that the recovery rate of pyrite increased with increasing activator dosage. The maximum recovery rate was 34\% when the dosage of the activator was $6 \mathrm{mg} / \mathrm{L}$. Then, under this dosage, the influence of the collector on the flotation recovery rate of pyrite was investigated. As shown in Figure $4 b$, the recovery rate of pyrite increased with increasing collector dosage. When the collector dosage reached a certain value, the recovery rate tended to be flat. The maximum recovery rate was $90 \%$ when the amount of collector was $20 \mathrm{mg} / \mathrm{L}$. When the dosage of activator and collector were optimal, the effect of frother on the recovery rate of pyrite flotation was studied. The test results are shown in Figure 4c. The best recovery rate was 95\% when the amount of frother was only $5 \mathrm{mg} / \mathrm{L}$. Figure $4 \mathrm{~d}$ shows that the $\mathrm{pH}$ value of pulp had a significant influence on pyrite flotation when the dosage of flotation reagents was fixed. Under acidic conditions, the recovery rate of pyrite increased by increasing the $\mathrm{pH}$ value of the slurry. Pyrite can be floated well when $\mathrm{pH}$ is between 3 and 7 , and the recovery rate was higher than $95 \%$ when the $\mathrm{pH}$ is about 6 . Under alkaline conditions, the recovery rate of pyrite shows a downward trend, and at a $\mathrm{pH}$ of 12 , it hardly increased.

Compared to a single reagent, the maximum flotation of pyrite was significantly increased with multiple reagents. This indicates that there is a strong synergistic effect between the flotation reagents that can substantially improve the recovery rate. In addition, the $\mathrm{pH}$ value had a coordinated inhibitory effect on the flotation of pyrite.

\subsection{Zeta Potential Analysis}

Zeta potential is an important means to characterize the surface electrical properties of minerals, and the addition of flotation reagents changes the surface potential of minerals. Figure 5 shows the zeta potential of pyrite before and after interaction with reagents at different $\mathrm{pH}$ values.

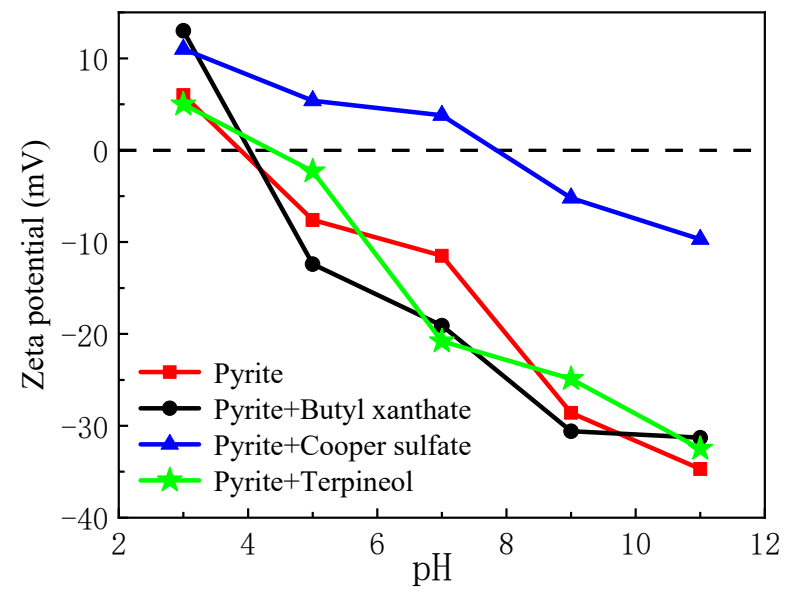

Figure 5. Zeta potential of pyrite particles as a function of $\mathrm{pH}$.

Figure 5 shows that the zeta potential on the pyrite surface shifted negatively throughout the $\mathrm{pH}$ range. The isoelectric point (IEP) of pyrite was found to be approximately $\mathrm{pH} 4$. Yin [21] reported that the isoelectric point of unoxidized pyrite was about $\mathrm{pH}$ 2, indicating that the surface of the pyrite used was oxidized during sample preparation and stirring. At $\mathrm{pH}<4$, the surface zeta potential of pyrite was positive. At $\mathrm{pH}>4$, the surface zeta potential of pyrite was negative. With increasing $\mathrm{pH}$ values, the absolute value of the zeta potential gradually increased. This is consistent with reports in the literature [22-24].

After adding butyl xanthate, the surface potential of pyrite decreased significantly at $\mathrm{pH}<7$. In the strong acidic range, the surface charge of pyrite was positive, and the negatively charged xanthate anions were adsorbed on the surface of pyrite [21]. Under strong alkali conditions, the oxidation of the pyrite surface and the intensified competitive adsorption of $\mathrm{OH}^{-}$promoted the formation of hydrophilic substances such as $\mathrm{Fe}(\mathrm{OH})_{3}$ [25], hindered the adsorption of xanthate, and reduced the surface potential of pyrite. After adding copper sulfate, the overall surface potential of pyrite moved 
positively, and the surface potential increased. This is because the positively charged $\mathrm{Cu}^{2+}$ or $\mathrm{CuOH}^{+}$ ions have electrostatic adsorption on the surface of pyrite [26]. With increasing $\mathrm{pH}$, the number of positively charged ions decreased, and the surface potential of pyrite became negative again. After the action of terpineol, the zeta potential on the pyrite surface shifted negatively with increasing $\mathrm{pH}$, and the absolute value of zeta potential gradually increased.

\subsection{Contact Angle Analysis}

The wettability of minerals is an important parameter of the surface properties, which is closely related to its floatability, and is generally characterized by a contact angle [27]. The contact angles of pyrite before and after the action of reagents under different $\mathrm{pH}$ values are shown in Figure 6.

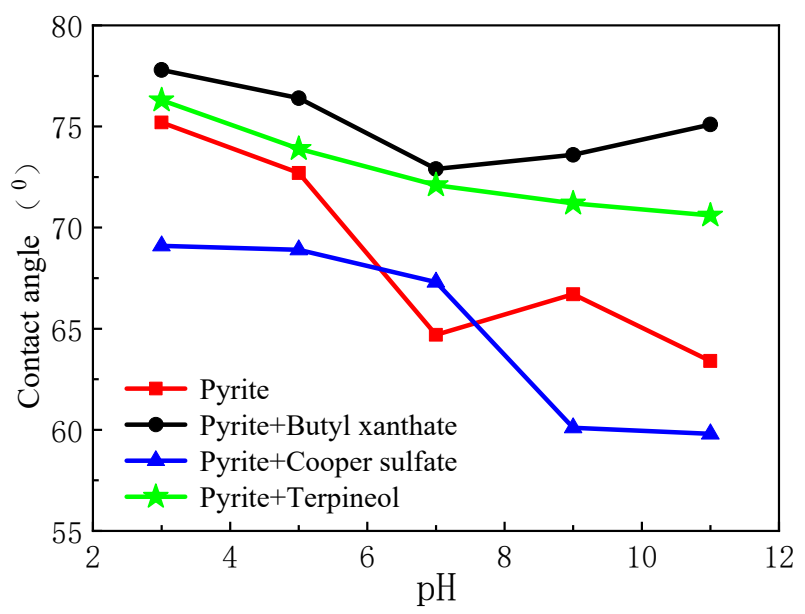

Figure 6. The contact angle of pyrite as a function of $\mathrm{pH}$.

The contact angle of the pyrite surface decreased with increasing $\mathrm{pH}$ values before reagents reacted with pyrite. The contact angle was at the minimum at $\mathrm{pH} 7$ and then rose slightly. This is because the hydrophobic S element was formed on the surface of pyrite under acidic conditions [28], and the hydrophobicity increases. Under the alkaline conditions, the hydrophilic substance of $\mathrm{Fe}(\mathrm{OH})_{3}$ was easily formed on the pyrite surface by oxidation, increasing the hydrophilicity of the pyrite surface and decreasing the contact angle.

The flotation reagents were able to change the wettability of the pyrite surface, and the contact angle changed significantly. After the interaction of butyl xanthate with pyrite, the contact angle of pyrite decreased first and then increased with increasing $\mathrm{pH}$ value. Under acidic and alkaline conditions, the adsorbed groups on the pyrite surface were $\mathrm{FeOH}^{+}$and $\mathrm{FeO}^{-}$, respectively. Under neutral conditions, there were only a few groups on the surface of pyrite for xanthate adsorption. This may be related to the intermediate $\mathrm{pH}$ inhibition zone after the action of butyl xanthate [29-32]. After copper sulfate reacted with pyrite, the contact angle on the pyrite surface decreased with increasing $\mathrm{pH}$ value. Under acidic conditions, $\mathrm{Cu}$ was adsorbed on the $\mathrm{S}$ site of pyrite by chemisorption $[33,34]$, weakening its hydrophobicity. Under alkaline conditions, the surface of pyrite tends to form hydrophilic substances such as $\mathrm{Cu}(\mathrm{OH})_{2}$, increasing the surface hydrophilicity and decreasing the contact angle [35]. After the action of terpineol, the contact angle of pyrite gradually decreased with increasing $\mathrm{pH}$ value.

\subsection{Assessment of Hydrophobic Agglomeration Behaviors}

The agglomeration of fine pyrite under the action of various reagents is shown in Figure 7. The effect of reagent-free pyrite was almost gradual and independent of particle distribution, with no apparent agglomeration phenomena. Compared to untreated pyrite, the pyrite particles showed a clear agglomeration phenomenon after flotation reagent treatment, indicating an improved surface hydrophobicity of pyrite. The results show that the pyrite agglomerates are the most compact after being treated with butyl xanthate and frother terpineol collectors. 

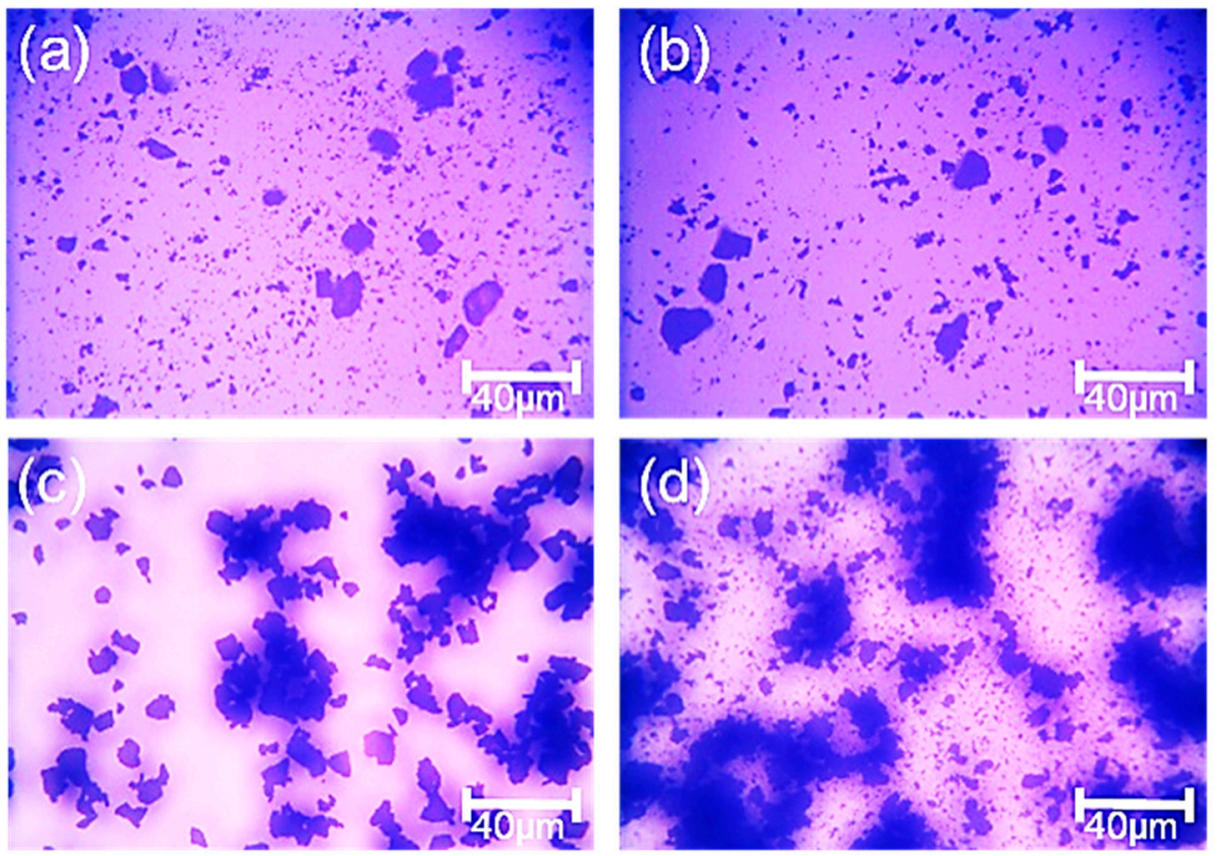

Figure 7. Distribution of fine pyrite under an optical microscope. (a) Pyrite + distilled water; (b) pyrite + copper sulfate; (c) pyrite + terpineol; (d) pyrite + butyl xanthate.

The effect of setting time on the hydrophobic agglomeration dynamics performance of pyrite suspensions under the action of different agents was also investigated. As shown in Figure 8, the turbidity showed a clear decreasing trend with increasing setting time. After the flotation reagent was used, the turbidity of the pyrite decreased. There was a reunion between them, which was easy to settle. The addition of butyl xanthate increased the hydrophobicity of pyrite particles, strengthened the hydrophobic attraction force between particles, and accelerated agglomeration. The order in which the reduction in pyrite agglomeration was affected by the addition of flotation reagents was butyl xanthate $>$ terpineol > copper sulfate.

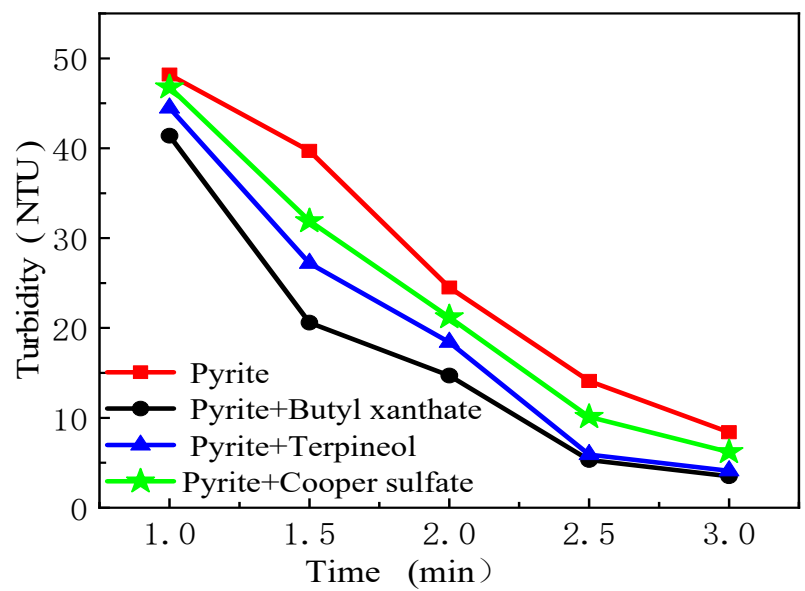

Figure 8. The turbidity changes over time with different flotation reagents. 


\subsection{Surface Energy and Interaction Energy Evaluation}

\subsubsection{Calculation and Analysis of Surface Energy}

The free energy of the solid surface can be calculated according to Young's equation by measuring the contact angle. Distilled water, glycerol and diiodomethane were used as examined liquids. The surface energy parameters [36,37] and contact angles are shown in Table 2.

Table 2. Surface energy parameters $\left(\mathrm{mJ} / \mathrm{m}^{2}\right)$ and contact angle $\left(^{\circ}\right)$ of examined liquid.

\begin{tabular}{ccccccc}
\hline Examined Liquid & $\gamma$ & $\gamma^{\mathrm{LW}}$ & $\gamma^{\mathrm{LB}}$ & $\gamma^{+}$ & $\gamma^{-}$ & Contact Angle \\
\hline $\mathrm{L}_{1}$ (Distilled water) & 72.8 & 21.8 & 51.0 & 25.5 & 25.5 & 76.4 \\
$\mathrm{~L}_{2}$ (Glycerol) & 64.0 & 34.0 & 30.0 & 3.9 & 57.5 & 16.6 \\
$\mathrm{~L}_{3}$ (Diiodomethane) & 50.8 & 51.8 & 0 & 0.7 & 0 & 0 \\
\hline
\end{tabular}

According to the contact angle measurement results and the surface energy parameters of the liquids examined, the surface energy parameters of pyrite can be obtained by substituting the data into Formula (5), as shown in Table 3.

Table 3. Surface energy parameters of pyrite $\left(\mathrm{mJ} / \mathrm{m}^{2}\right)$.

\begin{tabular}{ccccc}
\hline Surface Energy Parameters & $\gamma^{\mathrm{LW}}$ & $\gamma^{\mathrm{LB}}$ & $\gamma^{+}$ & $\gamma^{\mathbf{2 0 1 7}}$ \\
\hline Pyrite & 40.12 & 22.27 & 2.55 & 48.61 \\
\hline
\end{tabular}

From Table 3, it can be seen that the surface of the pyrite was a low-energy surface, with the non-polar Lifshitz van der Waals interaction $\gamma^{\mathrm{LW}}$ as the main component. The surface polarity of pyrite not only had Lewis alkali characteristics, but also a lot of Lewis acid components, and the Lewis base content was higher than the Lewis acid content. The pyrite surface presents certain amphoteric characteristics and is naturally hydrophobic. There was a certain relationship between the surface free energy of minerals and their floatability. Samples with higher alkali content showed a better wetting process for non-polar liquids. The measurement results of the contact angle just confirmed this.

\subsubsection{Calculation and Analysis of Interactions Energy between Pyrite Particles}

The radius $\mathrm{R}$ of the pyrite particles was $6.17 \mu \mathrm{m}$. The absolute dielectric constant $\varepsilon_{\mathrm{a}}$ of the dispersion medium was $6.95 \times 10^{-10} \mathrm{~F} / \mathrm{m}$, the Debye length $\mathrm{k}=0.104 \mathrm{~nm}^{-1}$, the minimum separation distance $\mathrm{d}_{0}=0.657 \mathrm{~nm}$ [36], $\mathrm{pH}$ of the system was 6 , and the temperature was room temperature. The hammack constant a is an important parameter to calculate the van der Waals interaction between macroscopic objects. $\mathrm{A}_{1}=7.10 \times 10^{-20} \mathrm{~J}$ for pyrite and $4.02 \times 10^{-20} \mathrm{~J}$ for water in vacuum. The interaction between particles in the flotation system occured mainly in the water medium, so $A=5.84 \times 10^{-20} \mathrm{~J}$. The contact angle $(\theta)$, zeta potential $\left(\varphi_{0}\right)$, incomplete hydrophobic coefficient $\left(\mathrm{k}_{1}\right)$, and attenuation length $\left(\mathrm{h}_{0}\right)$ are shown in Table 4.

Table 4. Results of surface contact angle and zeta potential of pyrite.

\begin{tabular}{ccccc}
\hline Samples & $\boldsymbol{\varphi}_{\mathbf{0}} / \mathbf{m} \mathbf{V}$ & $\boldsymbol{\theta} /{ }^{\circ}$ & $\mathbf{k}_{\mathbf{1}}$ & $\mathbf{h}_{\mathbf{0}} / \mathbf{n m}$ \\
\hline Pyrite + Distilled water & -32.18 & 76.37 & 0.46 & 5.15 \\
Pyrite + Butyl xanthate & -16.14 & 87.00 & 0.51 & 5.72 \\
Pyrite + Terpineol & -10.41 & 91.00 & 0.56 & 6.26 \\
Pyrite + Cooper sulfate & -1.80 & 47.00 & 0.33 & 3.65 \\
\hline
\end{tabular}

In the flotation process of mineral particles, surface and interface forces play an important role, including van der Waals force, electric double layer force and hydrophobic force. According to the extended-DLVO theory, the potential energy curve of interaction between pyrite particles in aqueous solution can be obtained as shown in Figure 9. 


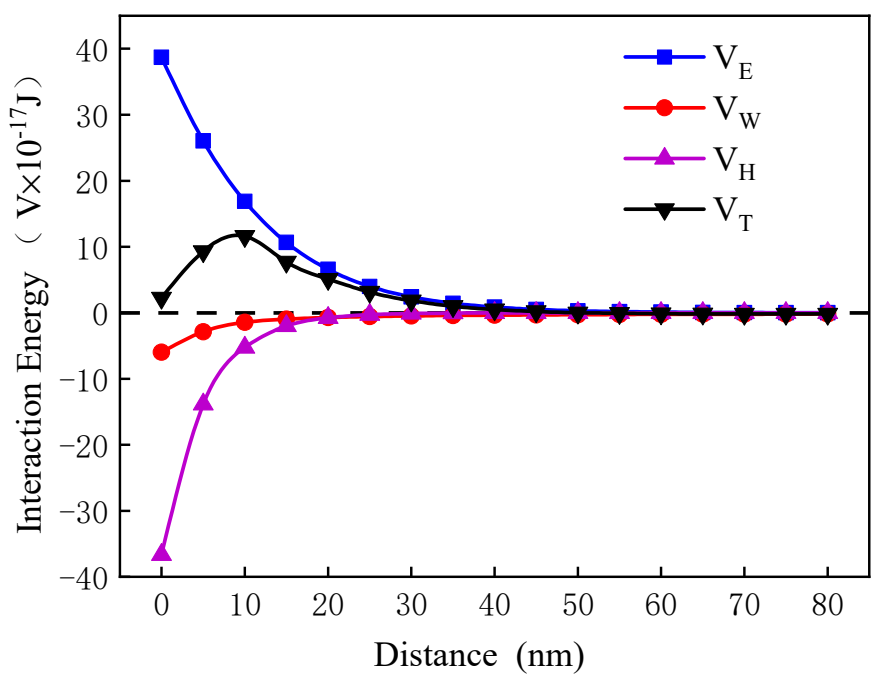

Figure 9. The extended-Derjaguin-Landau-Verwey-Overbeek (extended-DLVO) interaction energy between fine pyrite particles in aqueous solution.

In the aqueous solution, $V_{E}>0$, the electrostatic interaction energy was positive over the entire particle interaction distance, and there was repulsive potential energy between the particles. When $\mathrm{V}_{\mathrm{W}}<0, \mathrm{~V}_{\mathrm{H}}<0$, van der Waals interaction energy and hydrophobic interaction energy were negative. The potential energy between pyrite particles decreased with increasing distance. When the distance between particles was $0-50 \mathrm{~nm}$, the total interaction energy between pyrite particles in the aqueous solution was $\mathrm{V}_{\mathrm{T}}>0$, indicating that the particles were repulsive and the pyrite particles were in a dispersed state. As the distance between particles increased, the total interaction energy $\left(\mathrm{V}_{\mathrm{T}}\right)$ between pyrite particles increased first, and then decreased. When the distance was $5 \mathrm{~nm}$, the total interaction energy between pyrite particles reached a maximum of $1.98 \times 10^{-17} \mathrm{~J}$, and the maximum repulsive energy between particles was the largest. However, when particles were mainly the potential energy of electrostatic interaction, the interaction between particles appear as mutual repulsion, which is not conducive to the floating of pyrite.

In the process of flotation, the precondition of mineral separation is the adsorption of flotation reagents on the mineral surface, which changes the physical and chemical properties of the mineral surface. According to the Extended-DLVO theory, the electrostatic interaction energy, hydrophobic interaction energy and total action energy of pyrite before and after the action of reagents are further investigated in the aqueous solution environment. The results are shown in Figures 10-12.

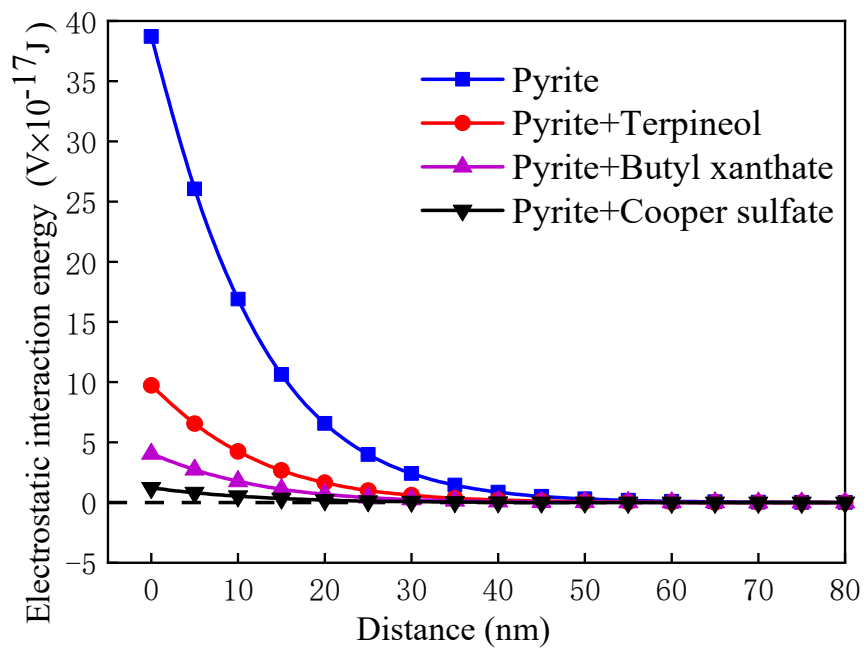

Figure 10. The electrostatic interaction energy between pyrite particles. 


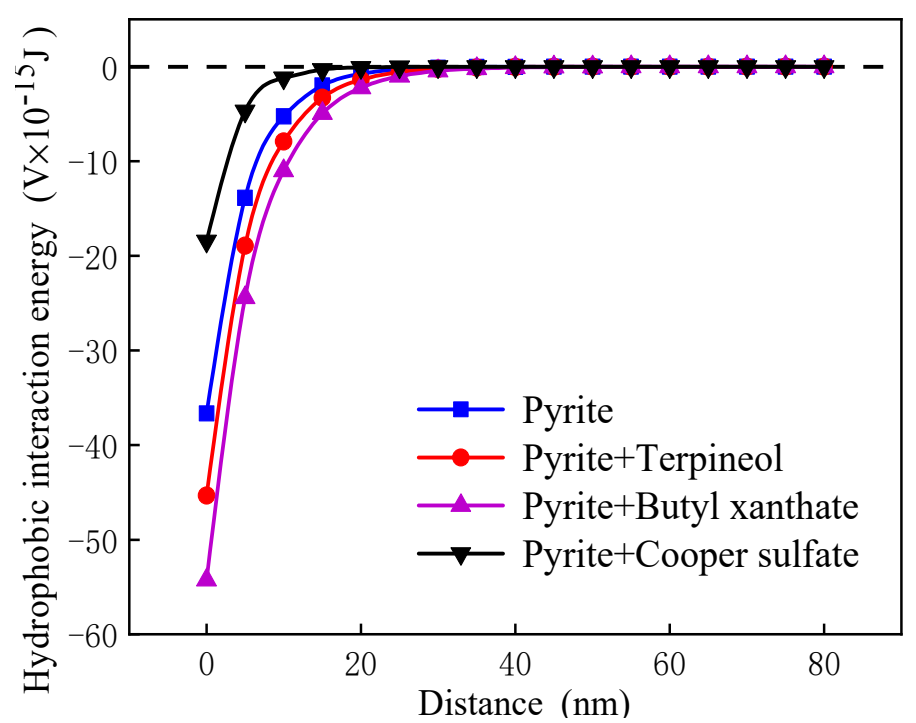

Figure 11. The hydrophobic interaction energy between pyrite particles.

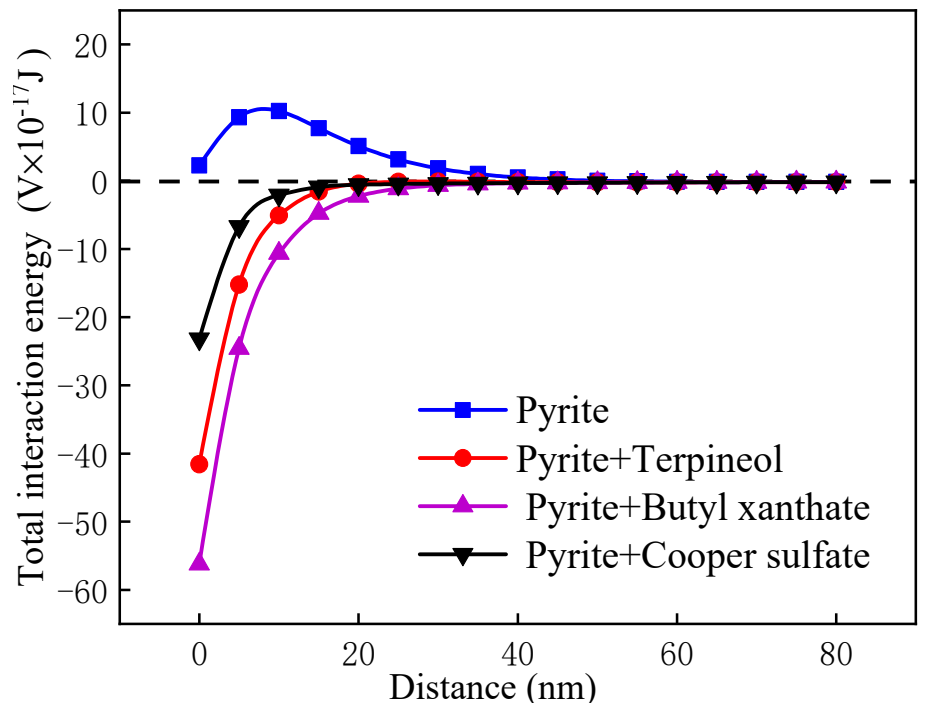

Figure 12. The total interaction energy between pyrite particles.

After the action of the medicament, the potential energy of electrostatic interaction between pyrite particles was significantly reduced. In the entire particle interaction distance, the electrostatic interaction energy between the pyrite particles before and after the reagents was $V_{E}>0$, indicating that the particles were repulsive energy. As the distance increases, the interaction energy tended to approach zero. The order of the electrostatic interaction energy between the pyrite particles caused by the flotation reagents was terpineol $>$ butyl xanthate $>$ copper sulfate.

After the action of the medicament, the potential energy of hydrophobic interaction between pyrite particles was significantly increased. After the flotation reagents interacted with the pyrite particles, the potential energy of the hydrophobic interaction between the particles increased. In the entire particle interaction distance, the hydrophobic interaction energy between the pyrite particles before and after the reagent was $V_{H}<0$, indicating that the particles were attracting energy. As the distance increased, the interaction energy tended to approach zero. The order of the hydrophobic interaction energy between the pyrite particles caused by different flotation reagents was butyl xanthate $>$ terpineol $>$ copper sulfate. 
There was always an "energy barrier" and a corresponding critical distance between the total potential energy of the pyrite particles. Before the action of the medicament, the total interaction potential energy between the particles was positive, showing mutual repulsion. As the distance decreased, the repulsion potential energy gradually rose to the "energy barrier". After the medicament interacted with pyrite, the peak value of the "energy barrier" dropped significantly. After the action of the collector, the total potential energy of the surface and interface of the pyrite particles was the largest. In the range of 0-30 $\mathrm{nm}$ between particles, as the distance between particles increased, the interaction force between particles was always negative, and the total interaction energy on the surface of pyrite particles decreased. When the distance between the particles was less than $20 \mathrm{~nm}$, the hydrophobic force between the particles increased sharply with the decrease of the distance, and agglomeration was likely to occur.

According to the above discussion, there was electrostatic repulsion energy, van der Waals attraction energy, and hydrophobic attraction energy between the pyrite particles before and after the effect of flotation reagents. The effect of flotation reagents on the agglomerate morphology in hydrophobic agglomeration is schematically represented in Figure 13. Among them, the van der Waals potential energy was small, and the hydrophobic potential energy played the central role. The calculation results show that the hydrophobic energy was two orders of magnitude larger than the electrostatic energy and van der Waals energy, promoting the mutual agglomeration of pyrite particles. When the distance between particles was less than $5 \mathrm{~nm}$, the most important contribution to the attraction energy of pyrite particles was the hydrophobic interaction energy between the particles, followed by the van der Waals interaction energy. This shows that the flotation reagents can control the interaction between pyrite particles. The reagents molecule mainly affected the hydrophobic agglomeration of pyrite particles by weakening the electrostatic interaction of the pyrite particle interface and strengthening the hydrophobic interaction potential energy.

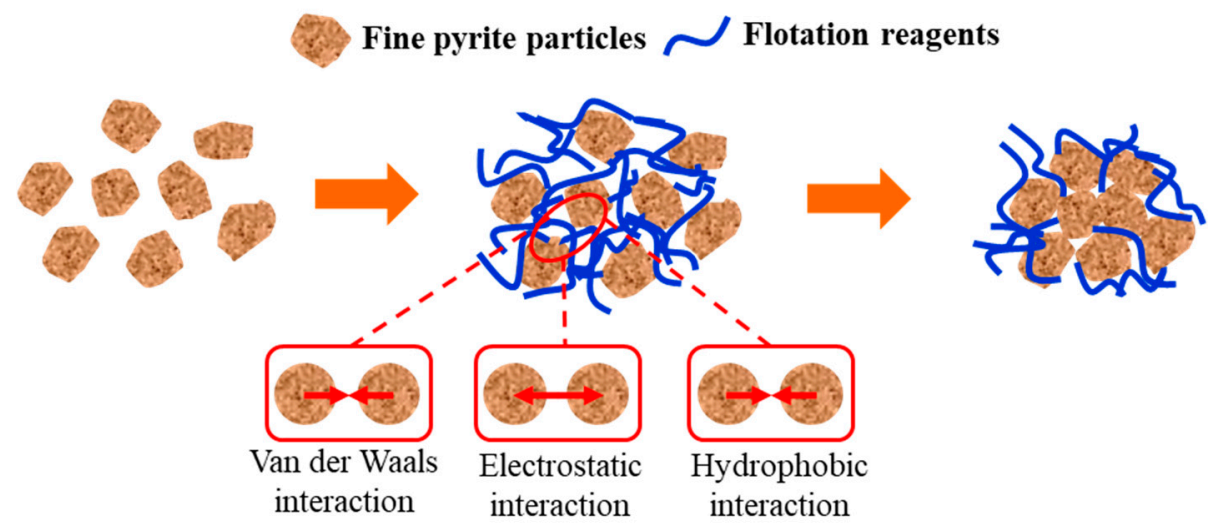

Figure 13. Schematic diagram of hydrophobic agglomeration of fine pyrite particles induced by flotation reagents.

\section{Conclusions}

Based on the extended-DLVO theory, this paper discusses the interaction of potential energy between fine pyrite particles. Some valuable original data were measured in this study, including the zeta potential, contact angle, and surface energy parameters of the pyrite surface with or without flotation reagents. These data can provide a reference for future research. In this study, the main conclusions are as follows:

(1) Flotation tests showed that when the dosage of the activator was $6 \mathrm{mg} / \mathrm{L}$, the dosage of a collector was $20 \mathrm{mg} / \mathrm{L}$, the dosage of frother was $5 \mathrm{mg} / \mathrm{L}$, and the $\mathrm{pH}$ value of the slurry was 6 , the maximum recovery rate of pyrite was $95 \%$. Compared to the simple addition of a single reagent, the maximum floatation of pyrite was significantly improved when multiple reagents 
worked together, indicating that there is a strong synergistic effect between flotation reagents, which can significantly improve the flotation environment and thus increase the recovery rate.

(2) Using the contact angle measurement method, the surface energy parameters of pyrite were obtained, in which the Lifshitz-van der Waals component was $40.12 \mathrm{~mJ} / \mathrm{m}^{2}$, the Lewis acid component was $2.55 \mathrm{~mJ} / \mathrm{m}^{2}$, and the Lewis alkali component was $48.61 \mathrm{~mJ} / \mathrm{m}^{2}$. The pyrite surface exhibited amphoteric properties, and the Lewis alkali component in the free energy polar component of the pyrite surface was much higher than the Lewis acid component, indicating better wettability.

(3) In the medium, the van der Waals potential energy and hydrophobic interaction potential energy between pyrite particles were always less than zero, and the particles appear to attract each other. In contrast, the electrostatic interaction potential energy was greater than zero, and the particles appeared to repel each other. Flotation reagents can change the surface charge and hydrophobicity of pyrite, and directly affect the interaction potential energy between the particles. Reagent molecules were able to significantly reduce the electrostatic repulsion potential energy at the interfaces of pyrite particles and increase the interface between particles. The hydrophobic attraction potential energy enhanced the surface hydrophobicity and played a leading role in the agglomeration between particles. It was also found that the collector butyl xanthate increased the hydrophobicity of pyrite and showed the strongest aggregation behavior.

Supplementary Materials: The following are available online at http://www.mdpi.com/2075-163X/10/9/801/s1, File S1: Calculation of Solid Surface Energy. References [38-44] are cited in the supplementary materials.

Author Contributions: W.C. and Z.D. conceived and designed the experimental scheme; W.C. performed all experimental work and wrote most of the manuscript; Z.D. participated in data analysis and writing. T.L. completed the flotation test; X.T. contributed experimental resources and participated in the manuscript modification. All authors have read and agreed to the published version of the manuscript.

Funding: Open project fund of State Key Laboratory for clean utilization of complex nonferrous metal resources jointly constructed by the Ministry and the province (No. CNMRCUKF1703).

Conflicts of Interest: The authors declare no conflict of interest.

\section{References}

1. Johnson, N.W. Liberated 0-10 $\mu$ m particles from sulphide ores, their production and separation-Recent developments and future needs. Miner. Eng. 2006, 19, 666-674. [CrossRef]

2. Koh, P.T.L.; Schwarz, M.P. CFD modeling of bubble-particle collision rates and deficiencies in a flotation cell. Miner. Eng. 2003, 16, 1055-1059.

3. Ninham, B.W. On progress in forces since the DLVO theory. Adv. Colloid Interface Sci. 1999, 83, 1-17. [CrossRef]

4. Yoon, R.H.; Mao, L. Application of extended DLVO theory, IV: Derivation of flotation rate equation from first principles. J. Colloid Interface Sci. 1996, 181, 613-626. [CrossRef]

5. Vincent, B. Early (pre-DLVO) studies of particle aggregation. Adv. Colloid Interface Sci. 2012, 170, 56-67. [CrossRef]

6. Song, S.; Lopez-Valdivieso, A. Parametric aspect of hydrophobic flocculation technology. Miner. Process. Extr. Metall. Rev. 2002, 23, 101-127. [CrossRef]

7. Lu, S.; Song, S. Hydrophobic interaction in flocculation and flotation 1. Hydrophobic flocculation of fine mineral particles in aqueous solution. Colloids Surf. 1991, 57, 49-60. [CrossRef]

8. Hu, Y.; Dai, J. Hydrophobic aggregation of alumina in surfactant solution. Miner. Eng. 2003, 16, 1167-1172. [CrossRef]

9. Vos, C.F.; Davidtz, J.C.; Miller, J.D. The effect of $\mathrm{nC}_{12}$-trithiocarbonate on pyrrhotite hydrophobicity and PGE flotation. J. S. Afr. Inst. Min. Metall. 2018, 118, 1095-1102. [CrossRef]

10. Vergouw, J.M.; Difeo, A.; Xu, Z.; Finch, J.A. An agglomeration study of sulphide minerals using zeta-potential and settling rate. Part 1: Pyrite and galena. Miner. Eng. 1998, 11, 159-169. [CrossRef]

11. Wen, P.L.; Zhou, L.Y.; Zhi, Y.D. Study on the Influence of Sodium Hexametaphosphate in Ultrafine Grinding of Pyrite. Conserv. Util. Miner. Resour. 2006, 06, 13-17. 
12. Liu, W.P.; Yin, Z.L.; Ding, Z.Y. Influence of liquid medium on ultrafine grinding of pyrite. Chin. J. Nonferrous Met. 2007, 17, 138-143.

13. Zhou, L.Y.; Zhi, Y.D.; Qi, Y.C. Study on Interaction among Pyrite Catalyst Particles Used in Direct Coal Liquefaction. Nonferrous Met. (Extr. Metall.) 2007, 06, 2-6.

14. Sagit, S.L.; Abraham, M. Validity and accuracy in evaluating surface tension of solids by additive approaches. J. Colloid Interface Sci. 2003, 262, 489-499.

15. Janczuk, B.; Bruque, J.M.; Gonzalez-Martin, M.L.; Roman-Galan, E. The contribution of double layers to the free energy of interactions in the cassiterite SDS solution system. Colloids Surf. A Physicochem. Eng. Asp. 1995, 100, 93-103. [CrossRef]

16. Oss, C.J.V.; Giese, R.F.; Costanzo, P.M. DLVO and non-DLVO interactions in hectorite. Clays Clay Miner. 1990, 38, 151-159.

17. Oss, C.J.V.; Chaudhury, M.K.; Good, R.J. Interfacial Lifshitz-van der Waals and polar interactions in macroscopic systems. Chem. Rev. 1988, 88, 927-941.

18. Van Oss, C.J.; Good, R.J. Surface tension and the solubility of polymers and biopolymers: The role of polar and apolar interfacial free energies. J. Macromol. Sci. Part A Chem. 1989, 26, 1183-1203. [CrossRef]

19. Oss, C.J.V.; Good, R.J.; Busscher, R.J. Estimation of the polar surface tension parameters of glycerol and formamide, for use in contact angle measurements on polar solids. J. Dispers. Sci. Technol. 1990, 11, 75-81. [CrossRef]

20. Liu, J.; Xu, Z. Role of Flotation Reagents in Tuning Colloidal Forces for Sphalerite-Silica Separation. Can. Metall. Q. 2013, 46, 329-340. [CrossRef]

21. Yin, W.; Xue, J.; Li, D.; Sun, Q.; Yao, J.; Huang, S. Flotation of heavily oxidized pyrite in the presence of fine digenite particles. Miner. Eng. 2018, 115, 142-149. [CrossRef]

22. Chai, W.; Huang, Y.; Peng, W.; Han, J.; Cao, Y.; Liu, J. Enhanced separation of pyrite from high-sulfur bauxite using 2-mercaptobenzimidazole as chelate collector: Flotation optimization and interaction mechanisms. Miner. Eng. 2018, 129, 93-101. [CrossRef]

23. Li, S.K.; Gu, G.H.; Qiu, G.Z.; Chen, Z.X. Flotation and electrochemical behaviors of chalcopyrite and pyrite in the presence of N-propyl-N'_Ethoxycarbonyl thiourea. Trans. Nonferrous Metals Soc. China 2018, 28, 1241-1247. [CrossRef]

24. Feng, B.; Feng, Q.; Lu, Y. The effect of lizardite surface characteristics on pyrite flotation. App. Surf. Sci. 2012, 259, 153-158. [CrossRef]

25. Bicak, O.; Ekmekci, Z.; Bradshaw, D.J.; Harris, P.J. Adsorption of guar gum and CMC on pyrite. Miner. Eng. 2007, 20, 996-1002. [CrossRef]

26. Ejtemaei, M.; Nguyen, A.V. Characterisation of sphalerite and pyrite surfaces activated by copper sulphate. Miner. Eng. 2017, 100, 223-232. [CrossRef]

27. Deng, W.; Xu, L.H.; Tian, J.; Hu, Y.H.; Han, Y.X. Flotation and adsorption of a new polysaccharide depressant on pyrite and talc in the presence of a pre-adsorbed xanthate collector. Minerals 2017, 7, 40. [CrossRef]

28. Peng, Y.; Wang, B.; Gerson, A. The effect of electrochemical potential on the activation of pyrite by copper and lead ions during grinding. Int. J. Miner. Process. 2012, 102, 141-149. [CrossRef]

29. López Valdivieso, A.; Sánchez López, A.A.; Song, S. On the cathodic reaction coupled with the oxidation of xanthates at the pyrite/aqueous solution interface. Int. J. Miner. Process. 2005, 77, 154-164. [CrossRef]

30. Fornasiero, D.; Ralston, J. Iron hydroxide complexes and their influence on the interaction between ethyl xanthate and pyrite. J. Colloid Interface Sci. 1992, 151, 225-235. [CrossRef]

31. He, S.; Fornasiero, D.; Skinner, W. Correlation between copper-activated pyrite flotation and surface species: Effect of pulp oxidation potential. Miner. Eng. 2005, 18, 1208-1213. [CrossRef]

32. Wang, X.H.; Forssberg, K.S.E. Mechanisms of pyrite flotation with xanthates. Int. J. Miner. Process. 2002, 33, 275-290. [CrossRef]

33. Weisener, C.; Gerson, A. An investigation of the $\mathrm{Cu}$ (II) adsorption mechanism on pyrite by ARXPS and SIMS. Miner. Eng. 2000, 13, 1329-1340. [CrossRef]

34. Boulton, A.; Fornasiero, D.; Ralston, J. Characterisation of sphalerite and pyrite flotation samples by XPS and ToF-SIMS. Int. J. Miner. Process. 2003, 70, 205-219. [CrossRef]

35. Chandra, A.P.; Puskar, L.; Simpson, D.J. Copper and xanthate adsorption onto pyrite surfaces: Implications for mineral separation through flotation. Int. J. Miner. Process. 2012, 114, 16-26. [CrossRef] 
36. Gu, G.H.; Wang, H.; Suo, J.; Qiu, G.Z.; Hao, Y. Interfacial interaction of bio-leaching of pyrite mineral. J. Cent. South Univ. Technol. 2008, 15, 49-53. [CrossRef]

37. Ming, Q.Z.; Qi, L.; Jiong, T.L. Extended DLVO theory applied to coal slime-water suspensions. J. Cent. South Univ. 2012, 19, 3558-3563.

38. Rudolph, M.; Hartmann, R. Specific surface free energy component distributions and flotabilities of mineral microparticles in flotation-An inverse gas chromatography study. Colloids Surf. A Physicochem. Eng. Asp. 2017, 513, 380-388. [CrossRef]

39. Wang, X.; Zhang, Q. Insight into the Influence of Surface Roughness on the Wettability of Apatite and Dolomite. Minerals 2020, 10, 114. [CrossRef]

40. Chen, Z.; Nosonovsky, M. Revisiting lowest possible surface energy of a solid. Surf. Topogr. Metrol. Prop. 2017, 5, 045001. [CrossRef]

41. Fowkes, F.M. Attractive Forces at Interfaces. Ind. Eng. Chem. 1964, 56, 40-52. [CrossRef]

42. Good, R.J.; Girifalco, L.A. A theory for estimation of surface and interfacial energies. III. Estimation of surface energies of solids from contact angle data. J. Phys. Chem. 1960, 64, 561-565. [CrossRef]

43. Hough, D.B.; White, L.R. The calculation of Hamaker constants from Liftshitz theory with applications to wetting phenomena. Adv. Colloid Interface Sci. 1980, 14, 3-41. [CrossRef]

44. Drummond, C.J.; Chan, D.Y.C. Van der Waals Interaction, Surface Free Energies, and Contact Angles: Dispersive Polymers and Liquids. Langmuir 2008, 13, 3890-3895. [CrossRef]

(C) 2020 by the authors. Licensee MDPI, Basel, Switzerland. This article is an open access article distributed under the terms and conditions of the Creative Commons Attribution (CC BY) license (http://creativecommons.org/licenses/by/4.0/). 